University of South Florida

DIGITAL COMMONS

@ UNIVERSITY OF SOUTH FLORIDA
Digital Commons @ University of

South Florida

\title{
Utilizing Information Technology in Innovative Marketing Approaches for Public Transportation
}

CUTR

Follow this and additional works at: https://digitalcommons.usf.edu/cutr_nctr

\section{Recommended Citation}

"Utilizing Information Technology in Innovative Marketing Approaches for Public Transportation," National Center for Transit Research (NCTR) Report No. CUTR-NCTR-RR-2008-05, Center for Urban Transportation Research, University of South Florida, 2010.

DOI: https://doi.org/10.5038/CUTR-NCTR-RR-2008-05

Available at: https://scholarcommons.usf.edu/cutr_nctr/147

This Technical Report is brought to you for free and open access by the National Center for Transit Research (NCTR) Archive (2000-2020) at Digital Commons @ University of South Florida. It has been accepted for inclusion in Research Reports by an authorized administrator of Digital Commons @ University of South Florida. For more information, please contact digitalcommons@usf.edu. 


\section{Utilizing Information Technology in Innovative Marketing Approaches for Public Transportation}

\section{Project \#BD549-53}

Prepared for the Florida Department of Transportation Research Center

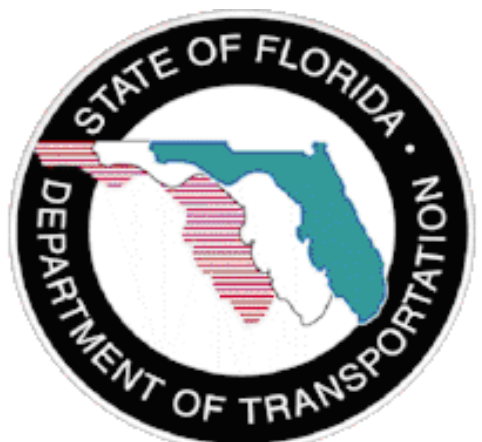

Prepared by the

National Center for Transit Research (NCTR)

Center for Urban Transportation Research

University of South Florida

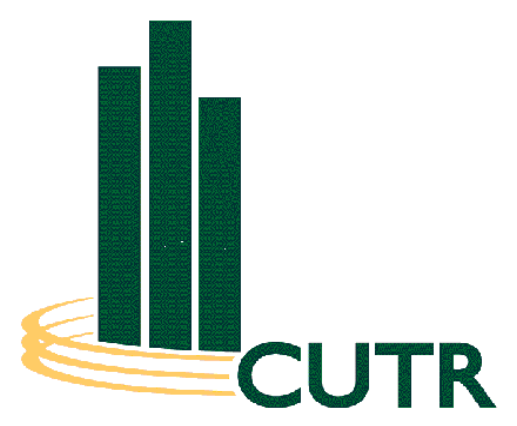

February 2010 


\section{Disclaimer}

The opinions, findings, and conclusions expressed in this publication are those of the authors and not necessarily those of the Florida Department of Transportation. 
Technical Report Documentation Page

\begin{tabular}{|c|c|c|c|}
\hline $\begin{array}{l}\text { 1. Report No. } \\
\text { BD-549-53 }\end{array}$ & 2. Government Accession No. & \multicolumn{2}{|l|}{ 3. Recipient's Catalog No. } \\
\hline \multirow{2}{*}{\multicolumn{2}{|c|}{$\begin{array}{l}\text { 4. Title and Subtitle } \\
\text { Utilizing Information Technology in Innovative Marketing } \\
\text { Approaches for Public Transportation }\end{array}$}} & \multicolumn{2}{|l|}{$\begin{array}{l}\text { 5. Report Date } \\
\text { December } 2009\end{array}$} \\
\hline & & \multicolumn{2}{|c|}{ 6. Performing Organization Code } \\
\hline \multicolumn{2}{|c|}{$\begin{array}{l}\text { 7. Author(s) } \\
\text { William P. Morris, Kelly Robertson, Jeremy Spinks }\end{array}$} & \multicolumn{2}{|c|}{ 8. Performing Organization Report No. } \\
\hline \multirow{2}{*}{\multicolumn{2}{|c|}{$\begin{array}{l}\text { 9. Performing Organization Name and Address } \\
\text { National Center for Transportation Research } \\
\text { Center for Urban Transportation Research } \\
\text { University of South Florida - CUT } 100 \\
4202 \text { East Fowler Avenue, Tampa, FL } 33620\end{array}$}} & \multicolumn{2}{|c|}{ 10. Work Unit No. (TRAIS) } \\
\hline & & \multicolumn{2}{|c|}{$\begin{array}{l}\text { 11. Contract or Grant No. } \\
\text { BD-539-53 }\end{array}$} \\
\hline \multirow{2}{*}{\multicolumn{2}{|c|}{$\begin{array}{l}\text { 12. Sponsoring Agency Name and Address } \\
\text { Office of Research and Special Programs (RSPA) } \\
\text { U.S. Department of Transportation, Washington, D.C. } 20590 \\
\text { Florida Department of Transportation } \\
605 \text { Suwannee Street, MS 26, Tallahassee, FL } 32399\end{array}$}} & \multicolumn{2}{|c|}{$\begin{array}{l}\text { 13. Type of Report and Period } \\
\text { Covered } \\
\text { Final Report }\end{array}$} \\
\hline & & \multicolumn{2}{|c|}{ 14. Sponsoring Agency Code } \\
\hline \multicolumn{4}{|l|}{ 15. Supplementary Notes } \\
\hline \multicolumn{4}{|c|}{$\begin{array}{l}\text { 16. Abstract } \\
\text { The original objective of this study is to scan the internet and other information technology sources to identify } \\
\text { innovative marketing techniques that have been attempted to date by, in and surrounding the public } \\
\text { transportation industry, and to solicit ideas for more unconventional applications that transit agencies and TDM } \\
\text { professionals can consider. The investigation led to the uses, applications, marketing and communications } \\
\text { potential of social media for the public transportation and Transportation Demand Management industries. } \\
\text { Social media afford low cost, high impact techniques that can be easily and quickly employed to reach target } \\
\text { markets and audiences. The study also provides tools, in the form of a guidebook and dedicated website, for } \\
\text { transit agencies to use the various social media for their own tailored marketing approaches. } \\
\text { Social media tools addressed in the study include social networks, weblogs, audio/video blogs, microblogs, photo } \\
\text { and video sharing, and user-generated content. In each, specific examples of applications for the public transit } \\
\text { and Transportation Demand Management industries is examined and explained. The guidebook provides clear } \\
\text { instructions for how agencies can utilize the media and the projected benefits, and is complete with embedded } \\
\text { links to resources and information. There is also a dedicated website, www.gosocialtransit.com that } \\
\text { accompanies the guidebook and provides an overview of each media and links to industry applications. }\end{array}$} \\
\hline \multirow{2}{*}{\multicolumn{2}{|c|}{$\begin{array}{l}\text { 17. Key Word } \\
\text { Social media, transit marketing, transit internet } \\
\text { marketing }\end{array}$}} & lent & \\
\hline & & $\begin{array}{c}\text { 21. No. of Pages } \\
90\end{array}$ & 22. Price \\
\hline
\end{tabular}

Form DOT F 1700.7 (8-72) Reproduction of completed page authorized 
Table of Contents

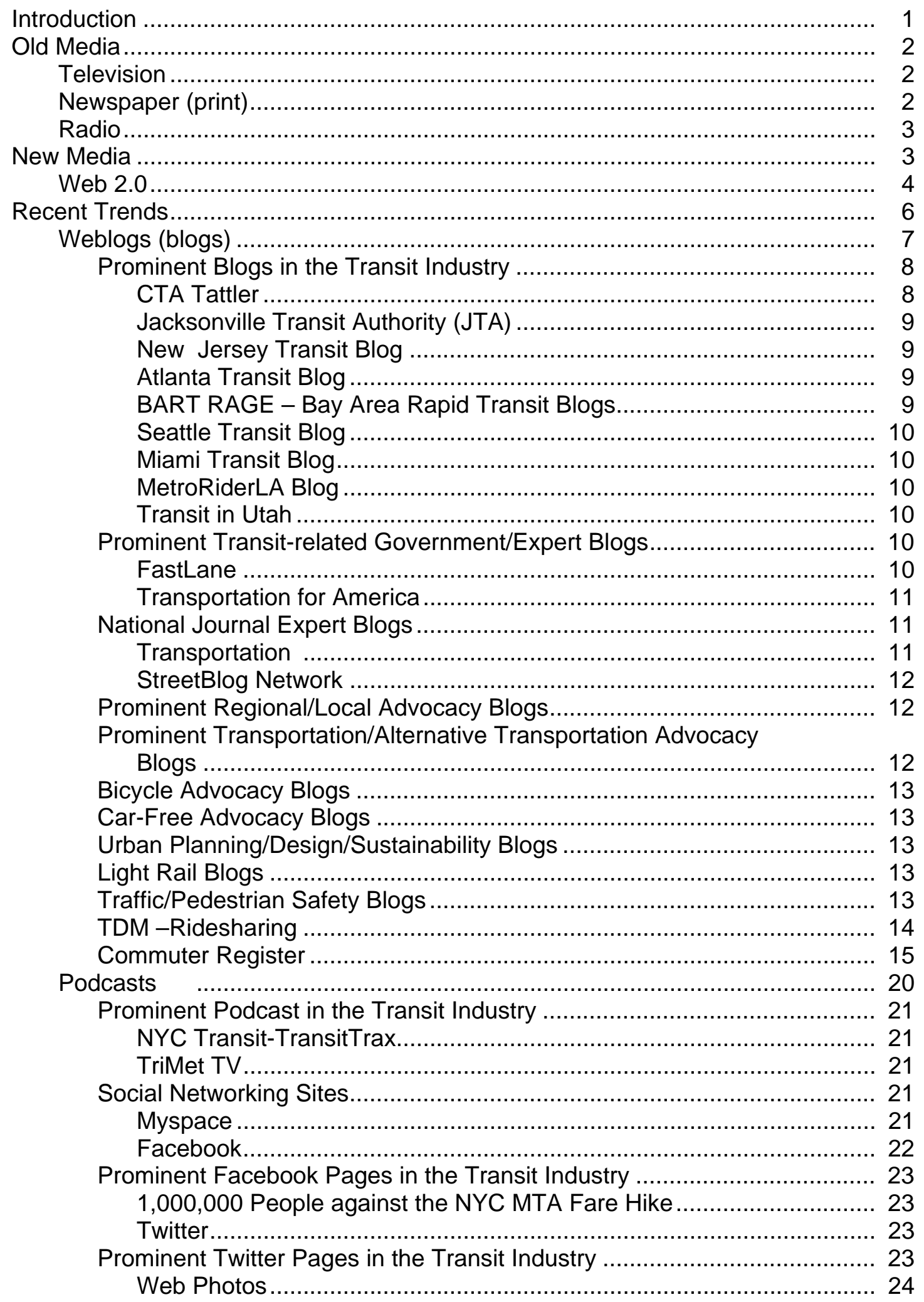


Prominent Flickr Pages in the Transit Industry..................................... 24

Web Video ............................................................................. 24

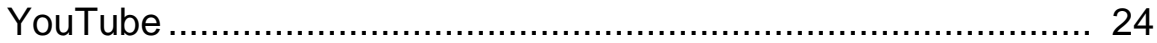

Transit Video Contests .................................................. 25

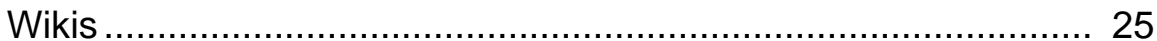

Prominent Wikis in the Transit Industry ............................................. 26

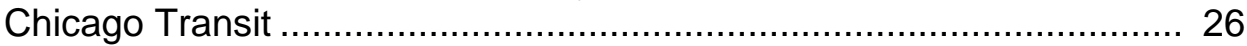

San Francisco Bay Area.......................................................... 26

Transit in Canada ............................................................................ 26

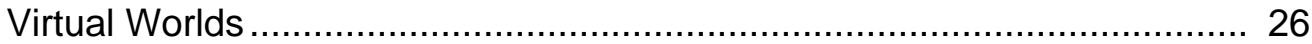

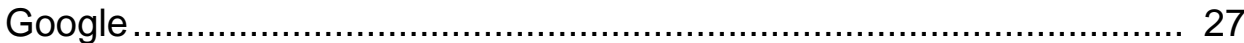

Google Transit........................................................................ 29

Google Maps ........................................................................... 30

Google Maps for Mobile ......................................................... 30

Google Maps for Phone .......................................................... 30

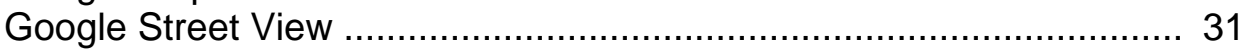

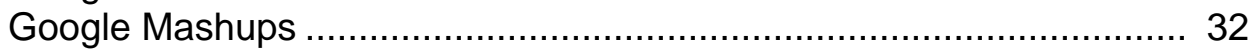

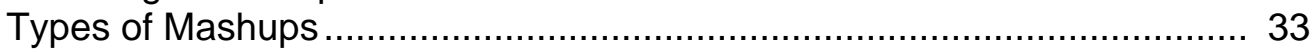

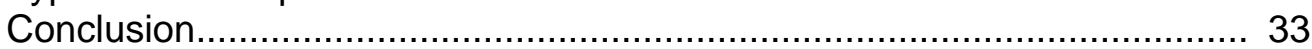




\section{List of Figures}

\section{Figure 1}

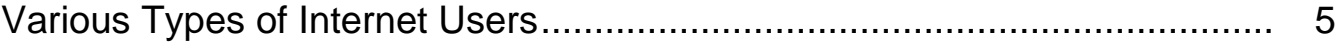

Figure 2

Media used by US Internet Users …............................................... 7 


\section{WHITE PAPER}

\section{Utilizing Information Technology in Innovative Marketing Approaches \\ for Public Transportation}

\section{Introduction}

Mass media, the ability to communicate with, inform and entertain large numbers of people, has been an ever-evolving form of communication in the United States and around the world. In 1704, the first daily newspaper began publishing in Boston. Although newspapers were the primary form of mass media, news traveled slowly between the colonies and later across an agrarian nation. In 1838, Samuel Morse transmitted the first telegram and by the late $19^{\text {th }}$ century, telegrams enabled information to move at a much faster rate. In 1895, the first commercially made motion picture premiered in the United States and in 1909 the first radio station began broadcasting in California. The radio and film industry reigned as the primary form of mass media through the mid-20 ${ }^{\text {th }}$ Century. In 1941 , the first television station was licensed in Pennsylvania and interestingly, 50 years later in 1991 the first website with a server was launched. After 1950, television became the largest form of mass media ever known; however, the internet has forever transformed all forms of mass media that preceded it.

On January 22, 2008 at approximately 3:30 p.m., the announcement was made that the actor Heath Ledger had died in New York. Within minutes, newspapers and news organizations around the world were reporting the actor's death. The internet has made communication virtually instantaneous. Copyrighted material, once the bastion of television, music and motion pictures, can be pirated and sold before they are premiered to audiences. For advertisers, the internet is so specialized that ads can be targeted to individuals based on the kinds of activities they engage in while using the internet. Gone are the days when audiences are passively waiting to have information and entertainment pushed at them through a screen. Now audiences are forming their own communities and their own forms of entertainment. Advertisers must seek out their target audiences if they wish to communicate their messages. Traditional media are now being called, "Old Media."

The public transportation industry in the past was largely dependent on newspapers, radio and television to advertise transit services within communities. The internet has 
brought about the New Media, or Social Media that necessitate the industry to adapt and benefit. In aggregate, social media is a group of websites that provide different and unique ways to have an online conversation. In this arena, consumers generate the news, trends, and topics. This is where many of transit agencies' and commuter services organizations' target audiences are already communicating. In fact, social media provide a means for people to be talking about transportation and mobility issues whether the industry is listening or not. Riders, residents, experts, and brand warriors alike can help spread your message.

\section{Old Media}

\section{Television}

The 1990's were a troubled decade for the Big Three TV networks, NBC, ABC, and CBS. For the first time since they began keeping records, their combined prime-time ratings dropped below 50 percent. There were many reasons for this change, but the most important one is that TV and the other older media are being challenged by the Internet and other technologies that offer an expanded range of information and entertainment services.

\section{Newspaper (print)}

Other media are similarly affected. For example, by the late 1990's, daily newspaper readership by adults had dropped from a post-World War II high of 78 percent to under 60 percent.

Figures released by the Newspaper Association of America show that the decline of newspapers is more rapid than previously thought, with total print advertising revenue in 2007 plunging $9.4 \%$ to $\$ 42$ billion compared to 2006 , the biggest drop in revenue since 1950 , the year they started tracking annual revenue.

Online provides some solace for the dead-tree business, with internet ad revenue growing $18.8 \%$ to $\$ 3.2$ billion compared to 2006 , but a rate significantly lower than the $31.4 \%$ growth the year before, and not even close to replacing the losses from print. Online revenue now represents $7.5 \%$ of total newspaper ad revenues.

Newspapers do have a future, but we have yet to see a major consolidation of print in the United States. Declining revenues will ultimately force consolidation across print 
media in the United States, and many of those that fail to embrace change will be on borrowed time. - (March 28, 2009 - Duncan Riley)

\section{Radio}

In 2008 the radio business experienced significant declines, with total revenues down $5 \%$ in the first half, to $\$ 9.86$ billion, and $6 \%$ in July, compared to the same periods last year, according to the Radio Advertising Bureau (http://www.rab.com).

The first-half decline was led by falling local and national revenues, down $6 \%$ to $\$ 6.98$ billion and $11 \%$ to $\$ 1.4$ billion, respectively. These figures are in line with recent survey results showing advertisers are cutting back on spending during the economic slowdown; traditional media like newspapers, radio, and magazines are taking some of the biggest hits.

Continuing another trend, radio stations in smaller markets performed much better than counterparts in midsized and larger markets, according to Jim Boyle, a radio analyst with CL King and Associates. Considered separately, radio stations in smaller markets saw revenue up $2 \%$ compared to last year, on average, while stations in mid-sized and larger markets are down 5\% and 7\%, respectively.

Smaller markets are faring better for a couple reasons. They were spared the fierce price wars which undercut big markets over the last two decades, as big radio groups battled for market share in major metro areas. In addition, small market stations often have closer relationships with local advertisers that tend to be more conservative in their media strategies. Aside from small markets, online is one of the few bright spots for radio, although its contribution to total revenue remains relatively small.

In the first half of 2008, the off-air ad category, which includes online, grew $12 \%$ to $\$ 889$ million. At this rate, the RAB claims off-air revenue should exceed $\$ 2$ billion by the end of the year. While this is welcome news for radio, the first half of the year contributed only $9 \%$ of total revenues.

\section{New Media}

As of 2000, the Internet was still in its infancy. Fewer than 25 percent of American consumers had access to its resources, but this is changing rapidly. (Dizard, 2000). 
Internet penetration is approximately 70 percent in the U.S. in 2008 -it still does not compete with TV yet - 98 percent, its coverage well blankets all but the oldest of generational segments and reaches even the elderly in affluent markets.

Mass media still accounts for the bulk of ad spending: television (44.1 percent), magazines (21.1 percent), newspapers (17.2 percent), radio (7.0 percent), and outdoor (2.6 percent). The internet accounts for 8 percent. Internet advertising has grown each year, while allocations to other media categories have consistently declined. The internet accounts for 20 percent of consumer media consumption. Given the current allocation of 8 percent of ad spending, continued growth in online advertising is practically a certainty.

Online advertising (Web 1.0) is diverse with numerous possible formats. These include paid search ads, display ads, classifieds, rich media, referrals, promotional email with embedded ads, and sponsorships.

In a Web 1.0 world, transit systems were pretty limited in the way they could market their services online. They all developed their own websites with information concerning their services including maps and schedules, rider guides, fare information, future projects, special services, etc.

\section{Web 2.0}

A relatively new development is the use of social media marketing. eMarketer estimates that social-media marketing will account for $10 \%$ or $\$ 2.9$ billion, in online advertising spending. Social media marketing is a broad category of advertising spending, including advertising using social networks, virtual worlds, user-generated product reviews, blogger endorsements, RSS feeds of content and social news sites, podcasts, games, and consumer generated advertising.

Why use social media marketing? Social media marketing offers these primary benefits: It can encourage interaction between consumers and brands. It can enhance perceptions of the "brand as person," thereby strengthening a brand's personality, differentiating a brand from its competitors, and setting the stage for a perceived relationship.

Social media refers to online communities that are participatory, conversational, and fluid. These communities enable members to produce, publish, control, critique, rank and interact with online content. Social Media is an umbrella term used for social 
networking sites, virtual worlds, social news and bookmarking sites, wikis, and forums and opinion sites.

The categories of social participation encompass activities ranging from the generation of original content to simply consuming content and go by the names (1) creators, (2) critics, (3) collectors, (4) joiners, (5) spectators, and (6) inactives.

\section{Figure 1}

\section{Various Types of Internet Users}

\begin{tabular}{|c|c|c|}
\hline Type & $\%$ & Common Activities \\
\hline Creators & 13 & $\begin{array}{l}\text { Active developers of content, who may publish websites, } \\
\text { maintain a blog, upload videos, etc. }\end{array}$ \\
\hline Critics & 19 & $\begin{array}{l}\text { Comment on blogs, respond to video posts, contribute to } \\
\text { product ratings and reviews, etc. }\end{array}$ \\
\hline Collectors & 15 & $\begin{array}{l}\text { Consume user-generated content actively (RSS feeds, } \\
\text { tagging sites), etc. }\end{array}$ \\
\hline Joiners & 19 & Participants in one or more social networks \\
\hline Spectators & 33 & $\begin{array}{l}\text { Consume media on a more passive level (i.e. reading blogs, } \\
\text { watching videos, listening to podcasts), etc. }\end{array}$ \\
\hline Inactives & 52 & Internet users not currently involved in social media \\
\hline
\end{tabular}

Source: Forrester Research North American Consumer Technographics, www.forrester.com

Social media marketing is rich with potential branding opportunities. What objectives can be met with social media marketing for transit?

- $\quad$ Build brand awareness (engage consumers)

- Develop ideas for new marketing strategies

- $\quad$ Drive traffic to corporate websites (and increase length of time at website)

- $\quad$ Garner publicity from news coverage of social media tactics

- Improve search engine rankings

- Enhance the image of the system

- Accomplish marketing goals with efficiency

- Research consumer behavior 


\section{Recent Trends}

In 2008, The Network TV news (NBC, CBS, ABC) is still used by the highest percentage of adult Internet users, with local newspapers and local TV news occupying the 2nd and 3rd positions, respectively, in a recently released survey from Ketchum.

While old media is still on top, the trends in the survey, which has been conducted each of the last three years, point to a familiar story: media consumption habits are quickly changing. That said, some forms of new media are performing much better than others. For example:

- Blogs are now used by $24 \%$ of Internet users, up from 13\% in 2006

- Social networks are now used by $26 \%$ of Internet users, up from $17 \%$ in 2006

- Videocasts are now used by $11 \%$ of Internet users, up from $6 \%$ in 2006

Slower growers include:

- RSS feeds: growing from 5 to 7 percent

- Podcasts: growing from 5 to 7 percent

- Business news sites: flat at 8 percent

Meanwhile, on the old media side of the house, some mediums are shrinking faster than others, with local TV news leading the decline, from $74 \%$ usage in 2006 to $62 \%$ last year. Cable news seems to be taking its place to some extent, growing from $47 \%$ to $49 \%$ usage in the same period. Here's the full chart, courtesy of eMarketer: 
Figure 2

Media Used by US Internet Users

\begin{tabular}{|c|c|c|c|}
\hline \multicolumn{4}{|c|}{$\begin{array}{l}\text { Media Used by US Internet Users, 2006-2008 (\% of } \\
\text { respondents) }\end{array}$} \\
\hline & 2006 & 2007 & 2008 \\
\hline Major network TV news & $71 \%$ & $65 \%$ & $65 \%$ \\
\hline Local newspapers & $69 \%$ & $62 \%$ & $63 \%$ \\
\hline Local TV news & $74 \%$ & $61 \%$ & $62 \%$ \\
\hline Search engines & $61 \%$ & $60 \%$ & $59 \%$ \\
\hline Cable network news & $47 \%$ & $46 \%$ & $49 \%$ \\
\hline Advice from family/friends & $44 \%$ & $43 \%$ & $47 \%$ \\
\hline E-mail newsletter & $40 \%$ & $35 \%$ & $42 \%$ \\
\hline Shopping Websites & $17 \%$ & $16 \%$ & $35 \%$ \\
\hline Talk radio & $36 \%$ & $26 \%$ & $31 \%$ \\
\hline Cable TV news Websites & $38 \%$ & $23 \%$ & $31 \%$ \\
\hline Advice from co-workers & $23 \%$ & $20 \%$ & $30 \%$ \\
\hline Social networking sites & $17 \%$ & $22 \%$ & $26 \%$ \\
\hline Company Websites & $22 \%$ & $19 \%$ & $26 \%$ \\
\hline Blogs & $13 \%$ & $19 \%$ & $24 \%$ \\
\hline National newspapers & $18 \%$ & $15 \%$ & $18 \%$ \\
\hline Consumer magazines & $23 \%$ & - & $18 \%$ \\
\hline Trade magazines or newsletters & $13 \%$ & - & $12 \%$ \\
\hline Videocasts & $6 \%$ & $7 \%$ & $11 \%$ \\
\hline Celebrity endorsement & $14 \%$ & $9 \%$ & $10 \%$ \\
\hline Company-sponsored e-mail blast & $7 \%$ & $5 \%$ & $9 \%$ \\
\hline Business news Websites & $8 \%$ & $8 \%$ & $8 \%$ \\
\hline Podcasts & $5 \%$ & $6 \%$ & $7 \%$ \\
\hline RSS news feed & $5 \%$ & $5 \%$ & $7 \%$ \\
\hline Mobile media & $5 \%$ & $4 \%$ & $6 \%$ \\
\hline \multicolumn{4}{|c|}{$\begin{array}{l}\text { Note: } 2008 \text { n=1,000 ages } 18+ \\
\text { Source: Ketchum and USC Annenberg Strategic Public Relations Center, } \\
\text { "Media Myths \& Realities:' } 2008 \text { Media Usage Survey," provided to } \\
\text { eMarketer, January } 20,2009\end{array}$} \\
\hline 101174 & & 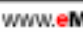 & \\
\hline
\end{tabular}

The declining usage for old media isn't much of a surprise. But looking at the growth rates for different forms of new media, it's apparent that some tools are catching on way faster than others, also not a surprise if you consider the topics we tend to focus on: social networking, blogging, and video. In all, the study re-enforces what you should be focusing on and prioritizing if you're responsible for getting a company up-and-running in the world of new media.

\section{Weblogs (blogs)}

A blog (a contraction of the term weblog) is a type of website, usually maintained by an individual with regular entries of commentary, descriptions of events, or other material 
such as graphics or video. Entries are commonly displayed in reverse-chronological order. "Blog" can also be used as a verb, meaning to maintain or add content to a blog. Many blogs provide commentary or news on a particular subject; others function as more personal online diaries. A typical blog combines text, images, and links to other blogs, Web pages, and other media related to its topic. The ability for readers to leave comments in an interactive format is an important part of many blogs. Most blogs are primarily textual, although some focus on art (artlog), photographs (photoblog), sketches (sketchblog), videos (vlog), music (MP3 blog), audio (podcasting), which are part of a wider network of social media. Micro-blogging is another type of blogging, one which consists of blogs with very short posts. As of December 2007, blog search engine Technorati was tracking more than 112 million blogs. With the advent of video blogging, the word blog has taken on an even looser meaning - that of any bit of media wherein the subject expresses his opinion or simply talks about something.

After a slow start, blogging rapidly gained in popularity. Blog usage spread during 1999 and the years following, being further popularized by the near-simultaneous arrival of the first hosted blog tools. Since 2002, blogs have gained increasing notice and coverage for their role in breaking, shaping, and spinning news stories. The Iraq war saw bloggers taking measured and passionate points of view that go beyond the traditional left-right divide of the political spectrum.

\section{Prominent Blogs in the Transit Industry}

\section{CTA Tattler}

http://www.ctatattler.com/

Focusing on the deep subculture of the El, buses, and Metra trains in the Chicago area, this public transit blog is a true community forum that features daily submissions from riders all over the Chicago area. Although they do spotlight CTA policy changes, legislative developments, construction, planning, and other issues that affect users of public transit, the real heart of the blog is in its snapshot of life on trains, on buses, and in CTA stations. The CTA Tattler chronicles the bizarre, offbeat, and often hilarious things that riders see, hear, and do. Readers will see tons of posts, consistent comments, and a combination of bemused, curious, admiring, critical, and just plain worthwhile information. You'll even find CTA gift ideas and a grassroots system for CTA rider alerts. 


\section{Jacksonville Transit Authority (JTA)}

http://jacksonvilletransit.blogspot.com/

\section{New Jersey Transit Blog}

http://blog.nj.com/transit/

NJ TRANSIT is the nation's largest statewide public transportation system providing more than 895,000 weekday trips on 240 bus routes, three light rail lines and 11 commuter rail lines. It is the third largest transit system in the country with 164 rail stations, 60 light rail stations and more than 18,000 bus stops linking major points in New Jersey, New York and Philadelphia. This blog chronicles the experience of a user of the system.

\section{Atlanta Transit Blog}

http://www.cfpt.org/blog.php

Maintained by Citizens for Progressive Transit, this site is aimed at information-sharing and activism within the Atlanta area, but they engage in discourse of national relevance. In their own words, they "strive to be an information conduit between our transit agencies and riders." The Atlanta Transit Blog demonstrates what an organized group of citizens can do to improve the world around them: they hold events, share their ideas with administrators and politicians, and educate the public about developing (and redeveloping) Atlanta in a transit-minded way. The organization and their public transit blog provide a model for progressives in other cities who want to advocate for smart growth and change.

\section{BART RAGE - Bay Area Rapid Transit Blogs http://www.bartrage.com/}

The purpose of this site is to create a community for BART riders who are willing to share good and bad experiences. Through this site we are hoping to share with other riders/employees and let our voices be heard to BART management that BART is important to commuters. We highly believe BART can improve their system and service by correctly utilizing our hard earned fare. We support BART because it cuts down on pollution and helps our environment. Please spread the word to other BART riders. Happy BARTing!!! 


\section{Seattle Transit Blog}

http://seattletransitblog.com/ - using Wordpress

\section{Miami Transit Blog}

http://www.transitmiami.com/

Website dedicated to discussing the transportation and urban planning problems that face the Miami region and Congestion Pricing Central, a new website geared to introducing the policies of road pricing programs.

\section{MetroRiderLA Blog}

http://metroriderla.com/

MetroRiderLA is a blog that promotes, supports, and critiques the burgeoning Transit Oriented Lifestyle forming in Los Angeles. It was created in order to inform the people of Los Angeles about their public transit system and to create a forum where news, information, and discourse can be gathered with the intent of improving the future of transit oriented mobility in our city.

\section{Transit in Utah}

http://transitinutah.blogspot.com/

Transit it Utah is dedicated to improving transit in the state of Utah especially along the

\section{Prominent Transit-related Government/Expert Blogs}

\section{Fast Lane}

http://fastlane.dot.gov/

This is the official blog of the U.S. Secretary of Transportation. This forum provides an opportunity for Department of Transportation officials to engage in a dialogue with interested citizens, members of the transportation community, and the blogosphere about our nation's transportation system. Fast Lane features commentary and observations from the Secretary and Administrators, contributions by guest bloggers from outside the Department, and even breaking news. 


\section{Transportation for America}

\section{http://t4america.org/}

Transportation for America has formed a broad coalition of housing, business, environmental, public health, transportation, equitable development, and other organizations. We're all seeking to align our national, state, and local transportation policies with an array of issues like economic opportunity, climate change, energy security, health, housing and community development - Issues that will play a key role in strengthening the foundation of our nation and give families and individuals greater and more appealing options.

We're a campaign on the move, marshaling other like-minded groups and resources together to bring about a better vision of America for the 21st century. They have hundreds of coalition partners across the U.S. including National, State, and Local Officials, Mayors, National Groups, and State, Regional, and Local Groups in 38 states.

\section{National Journal Expert Blogs - Transportation}

http://transportation.nationaljournal.com/

National Journal Group is the leading source of nonpartisan reporting on the current political environment and emerging policy trends. Our print, online and broadcast properties include National Journal, CongressDaily, The Hotline, NationalJournal.com, The Capital Source, The Almanac of American Politics, Convention Daily, "National Journal On Air" and "Washington Week with Gwen Ifill and National Journal ."

With 110 editors and reporters focused solely on Washington, National Journal Group's publications provide unmatched insight and set the editorial bar in political reporting. As a result, National Journal Group enjoys unparalleled readership loyalty from decision makers and policy influencers across the nation. National Journal Group's publications have become trusted professional resources for Members of Congress and their senior staffs, the Executive branch, federal agency executives, government affairs professionals, corporate and association leaders, and the political news media.

In the Transportation Journal, NationalJournal.com's Lisa Caruso leads a discussion among key policymakers and other experts on the issues facing the nation's transportation systems and infrastructure. 


\section{StreetsBlog Network}

http://streetsblog.net/

The Streetsblog Network is a national blog network focused on sustainable transport, smart growth and livable streets issues. It brings together nearly 300 blogs from all regions of the United States and beyond and highlights their best work. It is a one-stop shopping for transportation policy goodness.

Every member of the network is someone who blogs from a local perspective. They're writing about different cities, but talking to similar audiences and working towards similar goals. Together, this site reaches a weekly national readership that must number well into the hundreds of thousands.

\section{Prominent Regional/Local Advocacy Blogs}

Public Transportation/Alternative Transportation Advocacy Blogs

Citizens' Transportation Coalition http://www.ctchouston.org/

Green Wheels http://green-wheels.org/blog

Let's Go KC http://letsgokc.com/

Newton Streets and Sidewalks http://newtonstreets.blogspot.com/

One Less Car http://onelesscar.org/page.php?id=1

Portland Transport http://www.portlandtransport.com/

The Bus Bench (satirical) http://www.thebusbench.com/

Bus Chick (reader blog) http://blog.seattlepi.nwsource.com/buschick/

Boise Bus Blog http://boisebusblog.blogspot.com/

Xing Columbus http://xingcolumbus.wordpress.com/

\section{Bicycle Advocacy Blogs}

Austin Bike Blog http://austinbikeblog.org/

Bicycle Coalition of Greater Philadelphia http://bcgp.blogspot.com/

Bello Velo http://bellovelo.blogspot.com/

Bike Commute Tips http://bikecommutetips.blogspot.com/

Bike Denver http://www.bikedenver.org/

Bike PGH http://bike-pgh.org/

Bike Portland http://www.bikeportland.org/

Bike Providence http://bikeprovidence.org/

Boston Biker http://bostonbiker.org/

Chicagoland Bicycle Federation http://www.biketraffic.org/cbfblog.php

Concrete Lunch http://concretelunch.wordpress.com/ 
Flagstaff Biking Organization http://flagstaffbiking.org/

Fresno Bicycle Coalition News http://news. fresnobike.org/

Gary Rides Bikes http://garyridesbikes.blogspot.com/

LA County Bicycle Coalition http://lacbc.wordpress.com/

M-Bike.org http://www.m-bike.org/

Savannah Bicycle Campaign http://bicyclecampaign.org/

SF Bike Blog http://sf.bikeblogs.org/

Tempe Bicycle Action Group http://www.biketempe.org/

Tucson Bike Lawyer http://www.tucsonbikelawyer.com/

WashCycle http://washcycle.typepad.com/home/

\section{Car-Free Advocacy Blogs}

Car Free Days http://carfreedays.wordpress.com/

Car-Free Family http://carfreefamily.blogspot.com/

Carfree in Minneapolis http://carfreempls.blogspot.com/

Carfree USA http://carfreeusa.blogspot.com/

\section{Urban Planning/Design/Sustainability Blogs}

Beyond DC http://beyonddc.com/

Circles and Squares http://circleandsquares.blogspot.com/

Connecticut Smart Growth http://www.ctsmartgrowth.com/

Fort Worthology http://fortworthology.com/

Greater Greater Washington http://greatergreaterwashington.org/

GreenCityBlueLake http://www.gcbl.org/

LA Visions http://lavisions.blogspot.com/

Preserving Savannah Neighborhoods http://psnsav.org/

Rethink College Park http://www.rethinkcollegepark.net/blog/

Sustainable Savannah http://sustainablesavannah.com/

Urban Indy http://urbanindy.blogspot.com/

Urban Milwaukee http://urbanmilwaukee.com/

\section{Light Rail Blogs}

KC Light Rail http://kclightrail.com/

Light Rail AZ http://www.raillife.com/blog/

\section{Traffic/Pedestrian Safety Blogs}

New Haven Safe Streets http://www.newhavensafestreets.org/

Pedestrian Advocates of the Coastal Empire http://www.pacesavannah.org/

PEDS http://peds.org/ 
Rights of Way http://rightsofway.blogspot.com/

TranTwin Cities Streets for People http://tcstreetsforpeople.org/

\section{TDM - Ridematching}

Commuterpages.com

Transportation choices in the Washington D.C. area.

\section{AlterNetRides.com}

An innovative rideshare solution that works nationwide but also can be tailored for a community. Appropriate agencies (i.e., TMA's) can be set up as a "Sponsor" and, in turn, they set up the destinations for the community they support. Completely automated, a person can become a member, set up a ride and be viewing others wanting to rideshare in just minutes. Sponsors have access to the metrics of how many people are signing up, how many matches, etc. Sponsors can involve more of the community by creating customized "Welcome" pages for specific locations that can display that organization's banner. Plus additional "Sponsor ID"s can be set up to let the transportation specialists of organizations check the metrics of their location. (10/30/03)

Carpool Application on $\quad$ Facebook

http://www.facebook.com/apps/application.php?id=2549790782

Facebook's Carpool Application (powered by Zimride) is an online ride-sharing service that leverages Google Maps, a proprietary ride-matching algorithm and the trust building capacity of Facebook. The intuitive application proactively builds the critical mass of users necessary to establish a reliable form of transportation at your university or corporation. Carpool on Facebook is customized for your organization to deliver a new form of transportation to reduce costs, traffic and emissions.

\section{Carpoolconnect.com}

A carpooling commuters' search engine. Commuters are matched up based on similar commutes defined by home and work zip codes.

\section{Carpoolworld.com}

Carpoolworld.com uses the commuter's precise latitude and longitude coordinates, easily available and free, to find the best matches for their trip among the other commuters in the database, based on exactly how close together they live and exactly how close together they work. The system works efficiently everywhere on Earth. Originally launched in November 2000, and already having several hundred users, the new version of carpoolworld.com, put online in July 2001, has a clean new look and includes several significant new features. The system now tells the commuter whether 
he or the other commuter should be the driver, has improved latitude and longitude look up functions, offers an inexpensive partnership program for other website operators, and even provides a PC version of its trip matching software as a shareware download. The system also includes features to maximize the user's privacy and minimize potential abuse.

\section{Commuter Connections - https://www.carpool.cal}

This secure ridematching and rideshare management program is available via the internet. Matches are based on user defined proximity, a variety of personal preferences, and time of commute. This self-serve system has various levels of security, limiting individual access to personal rideshare information while providing rideshare program administrators broader access. The program includes a built in $\mathrm{CO} 2$ savings calculator. Rideshare program administrators can add custom fields, contact users via e-mail, manage pool groups and access a variety of reports. To ensure active membership, the system generates monthly reminders to participants.

\section{Commuter Register}

http://www.2plus.com

This multimedia commute option information and matching publication provides: listings of car and vanpools, transit routes and schedules, park and ride lots, and articles and helpful travel tips. Commuter Register is a product of 2Plus, Inc.

\section{Ecolane Dynamic Carpool - http://www.ecolane.com/}

This modern and innovative solution for corporations and business parks promotes carpooling as an alternative for commuters. It enables commuters to overcome the biggest obstacles of traditional carpooling today - irregular working schedules and finding a carpool partner. Commuters are able to select if they want to rideshare in as little as 15 minutes and create an instant carpool with the mobile phone or web-based applications. The Ecolane Dynamic Carpool software communicates the needs of both drivers and passengers, and automatically matches potential carpoolers in real-time. Finding a carpooling partner is much easier as the need for a fixed schedule is eliminated. Matching is based on digital maps, individual profiles, user groups, and user ratings.

\section{eCommuter.com}

An internet-based technology application specializing in Real-Time Internet traveler solutions. It is the first-to-market in the category of self-serve Internet ride-matching, that gives end-users the power to find their own partners for sharing a carpool or vanpool to 
work - without any human intervention. The application provides a secure logon to a confidential database that has a self-cleaning mechanism to ensure the database has only active members.

\section{eRideShare.com}

A free service for connecting commuters, or travelers going the same way. It's a good way to commute or travel inexpensively, and maybe even make a few friends, while reducing pollution, traffic, and dependence on oil. According to Yahoo and Google, eRideShare.com is the top national ridesharing site, and it was rated "Best of the Net" by About.com.

\section{Goose Networks.com}

Goose Networks, Inc. is a Seattle-based technology firm developing innovative solutions to the challenges of everyday transportation. 'GOOSE' is Goose Networks' service to help commuters create a network of rideshare partners and share rides with them when convenient. An easy-to-use website helps users to plan trips in advance, or users may plan trips on-the-go via simple text messages sent from their mobile phone. For commuters, GOOSE Express (www.readysetgoose.com) allows users to create their own ridesharing networks with designated meeting points. For organizations, GOOSE Professional (www.goosenetworks.com) is a customizable commute management system offering a branded web-portal, powerful reporting, customizable rewards programs and integration with other transit programs such as vanpools, public transportation and guaranteed ride home (GRH).

\section{GreenRide}

GreenRide (www.greenride.com) is a web and map based rideshare solution that provides instant ridematching which respects user privacy. GreenRide frees up administrators to market their TDM program to increase participation rather than managing the ridematching process. GreenRide has additional capabilities including dynamic content editing, along-route and radius matching, custom employer portals, multi-tier reporting, alternative language options, vanpool management, $\mathrm{GRH}$, and instant matching up to carpoolers, vanpools, transit stops, park-and-ride lots, and bicycle routes. GreenRide utilizes Geographic Information System (GIS) technology from ESRI. 


\section{iCarpool}

iCarpool (www.iCarpool.com) is a Seattle, WA based company which provides online and custom branded hosted solutions for comprehensive commuter choice programs for employers and regional public agencies. iCarpool's ride matching application provides user friendly, self service usage complete with interactive maps, privacy protection, high precision trip matching and support for all trip types such as daily commute, one time trips or real time (dynamic carpool) trips. The application also supports - multiple modes such as carpool, vanpool, bike, walk and transit, integrated GIS data such as park-andride lots, bike routes, multi modal trip calendar and integrated incentives provided by either employers or regional public agencies / TMAs / TMOs. iCarpool also provides administration capabilities at the employer level and the regional agency / TMA / TMO level to manage the program, provide and manage incentives such as $\mathrm{GRH}$, Vanpool Financial Stipend, Carpool Permit or custom incentives. The administration applications provide tracking and reporting of emission savings, monetary savings, trip reduction details and powerful reporting tools. iCarpool also provides first-of-a-kind ability to extend program outreach and interest of regional programs through innovative high tech applications such as social networking and mobile phones.

MyCasualCarpool.com helps users find others with similar daily commuting patterns and create rideshare lots using only resources available in virtually every residential neighborhood. The site is especially useful to large employers drawing workers from a large geographical area. Although no employer involvement is required, such involvement greatly improves the likelihood that "casual" carpools will be formed as more workers become aware of the site.

\section{NuRide}

NuRide is the nation's first incentive-based ride network that rewards people every time they share a ride. Through the NuRide Network ${ }^{\circledR}$, individuals can easily arrange individual ridesharing trips for work or pleasure and earn rewards for every confirmed trip they take. Unlike a traditional carpool, NuRide is flexible and casual with users being able to share a single ride without any ongoing commitments. Participants earn "NuRide Miles", our exclusive reward points that can be redeemed for gift cards, gift certificates and other rewards from corporate sponsors.

\section{Pathway Intelligence, Inc.}

Since 2001, Pathway Intelligence has been developing and delivering ridematching technology on a Canada-wide basis to the public, private employers, as well as regionally licensed systems in Metropolitan Toronto and Ontario (www.carpoolzone.ca) and British Columbia, Canada (online.ride-share.com). Our software arose as an 
initiative from within the TDM sector and has continued to grow and evolve in this context according to the commute program needs and priorities of our clients. The Pathway Commuter Platform offers regions, TMAs, institutions, and employers a customized and cutting-edge complete commute management system that is simultaneously simple and user friendly. An intuitively designed and multilingual user interface is paired with a powerful administrative back-end for compellingly accurate results reporting, streamlined program management, and support for multiple skinned sites for tiered-groups (i.e. networks of TMAs) with both individual and aggregate administration. Integrated platform modules include Pathway En-Route: a Google-maps and geocode based ridematching solution; Pathway Rewards: a calendar-based incentive tracking system with support for all non-SOV modes; and Pathway SureRide: online emergency ride home registration and administration. System reports include tangible measurable results (i.e. emissions and miles saved) achieved through automated tracking and reporting of users' actual carpooling habits. Additional integrated platform features include vanpool clustering, vanpool management support, user satisfaction survey and message engine.

\section{Ride Now!}

This "instant-match" service encourages and makes it easier for current solo drivers to carpool. Web and cell-phone technology makes it flexible and convenient; parking space incentives encourage drivers to give dynamic ridesharing a try, and to continue using the service. Ride Now differs from traditional car pools; in this system, users do not form regular carpools. Instead, each ride match request is the basis for potentially new carpool arrangements. The system can give users a ride match within a very short time (say, 10 minutes). The idea is that with sufficient volume the system works very flexibly and conveniently for users, while using car pool parking spaces as an incentive for people to use the system. By enabling current drive-alone commuters to carpool, the system will free up parking spaces. The Ride Now system includes both web and telephone ("Interactive Voice Response") interfaces.

\section{$\underline{\text { RidePro }}$}

RidePro is an integrated desktop and web based rideshare information solution. RidePro's local area network interface is a comprehensive, client-server, menu-driven, Windows ${ }^{\circledR}$-based application with integrated GIS mapping, Guaranteed Ride Home tracking, vanpool driver and roster tracking, vanpool cluster analysis, marketing module, and 25 pre-defined reports (including activity summary, community benefits, mode use analysis, etc.). Special Features include sending the output of RidePro's rideshare match report directly to an e-mail message. RidePro's web interface allows the public to create their own registrations and run their own match reports in a secure, confidential 
environment. The web component of RidePro uses the same database as the local area network interface, eliminating the need to reconcile different databases. Both interfaces support matching to carpools, vanpools, park-n-ride lots, public transit, telecommute centers, day care centers, bike partners, and bike routes.

\section{RideshareOnline.com}

This Seattle-based online ridematching system is simple. After typing in their email address and choosing a password, users enter their work location and the starting point of their commute - either a home address or a nearby intersection. To preserve privacy, home addresses are not displayed publicly. They enter their weekly work schedule and any daily variations. By return email they receive a confirmation code to complete their registration. They can instantly see a list of rideshare matches to whom they may email a rideshare request.

\section{RideShark}

RideShark (www.RideShark.com) is a low-cost online map-based rideshare solution that enables registrants to find rideshare partners based on customized search criteria. It is the only system to offer true route matching. Banking grade security ensures data protection and user privacy. The RideShark product group includes ridematching based on a regional, TMA or secure cluster or private organization. RideShark includes modules for matching for carpooling, vanpooling, bicycling, walking and transit, a ERH module, RideShark Tracks for commuter incentive programs and RideShark Business Travel matching. RideShark is multi-language enabled and has a comprehensive multitier administrative portal. RideShark utilizes Geographic Information System (GIS) technology from Microsoft MapPoint, and developed by a Microsoft Gold Certified Partner.

\section{Seattle Smart Traveler (SST)}

The Seattle Smart Traveler was the ridematching component of the Seattle Wide-area Information for Travelers (SWIFT), Model Deployment Initiative project and demonstrated the ability to use advanced communications networks to facilitate dynamic ride sharing for employees of a large organization.

\section{SharetheDrive.org}

The Chicago Area Transportation Study uses its proprietary RM 21 route-based carpool I vanpool ridematching software system to power its program in northeastern Illinois. This system departs from typical "mile-radius" searching by allowing users to chart their travel path. This path is then used to find matches of varying quality as determined by sameness of route, closeness of schedule, and matching of individual preferences. After 
registering, users are asked via automated emails about their satisfaction and continued participation in SharetheDrive.org. Administrators are able to use the RM 21 software to produce reports, conduct periodic surveys, and email information to rideshare applicants. A privacy policy is disclosed, and users, once registered,are taken to a secured site to search for new matches or update information. For more information, please contact Jose Rodriguez at irodriguez@catsmpo.com

\section{Visual BACSCAP 2007}

A user-friendly transportation program designed by the Marketing Institute at Florida State University College of Business for use by commuter assistance programs. The primary function of the program is to provide commuters with information regarding pools. Creates and tracks successful pool formation. Demographic information about the pool can be stored in the database and accessed by the user. Provides the ability to create maps, reports, and statistical information regarding applicants as well as their employers. Another important feature of Visual BACSCAP is its Guaranteed Ride Home Program compatibility. You can view the online demo, EzRide, at http://nctr.cob.fsu.edu/ezridedemo/login.asp

\section{VivaCommute}

Provides web-based commuter rideshare services for all geographical locations in Canada and the United States. This web-based application matches people who travel the same route and share the same driving schedule. The system is easy to use, minimizes travel through the use of nearest neighbor logic, provides security through the use of anonymous nicknames, Uses personalized Web pages for each commuter group and supports and encourages local sponsorships. The firm offers three commuter models to choose from: regional model, fixed destination model, and closed user group model.

\section{Podcasts}

A podcast usually consists of a combination of audio and/or video that is made available for download via syndication. It is this syndication aspect of the delivery that separates a podcast from a file available for download. The files are usually retrieved with software applications (generically known as podcatchers) such as Apple's iTunes so that subscribers can listen at their convenience on devices that have intermittent, slow, or are otherwise lacking Internet access. The podcatcher reads an [RSS] feed (whose entries point to specific podcasts, usually sorted by date) to identify and retrieve the podcast. 
Like the term broadcast, podcast can refer either to the content itself or to the method by which the content is syndicated; the latter is also called podcasting. A podcaster is the person who creates the content.

A podcast is syndicated via an RSS feed. This feed enables distribution over the Internet by syndicated download. Though the same content may also be made available by direct download or streaming, a podcast is distinguished from most other digital media formats by its ability to be syndicated, subscribed to, and downloaded automatically when new content is added.

\section{Prominent Podcast in the Transit Industry}

\section{NYC Transit - TransitTrax}

http://transittrax.mta.info/audio/transittrax.htm

Hear tips for staying safe, service advisories, MetroCard Deals information - even interviews with special guests. If a particular topic area interests you, just click on the corresponding link to subscribe to that particular category. They're updated constantly, so you'll always receive something new. Subscribe to one or as many as you like.

\section{TriMet TV}

http://trimet.org/tv/index.htm

Trimet TV is a video podcast featuring news about TriMet services and transit construction projects.

\section{Social Networking Sites}

\section{MySpace}

MySpace is a general social networking site with more than 100 million registered profiles and unique visitors exceeding 50 million per month. MySpace was initially intended for an audience of teens and young adults, but MySpace's age demographic is distribute over a range of ages with its largest category being the 35-54 age group (54 percent of its user base). A strength of MySpace is its broad appeal, developing at least in part due to its vast array of features, including individual profiles, music, video, instant messaging, blogs, groups, communities, and a host of others. To date, MySpace is the most successful network in leveraging the network effect or basically the effect that the network gains value as more people join. A recent addition to MySpace has been targeted ads based on user profiles. It has experienced a recent drop-off in many key 
metrics as rival Facebook has become the social network of choice for a greater percentage of users.

\section{Facebook}

Facebook has recently overtaken MySpace in monthly unique visitors in January 2009 and in some other key metrics even earlier (in 2008) to become the most popular social network on the internet. When facebook launched in February 2004, it focused on high school and college students, relying on existing tangible networks to build the virtual network base. It has been enormously successful with the college audience (upwards of 85 percent of college students have used it), but since that time it opened the site to non-students, expanded to other countries and hasn't looked back. Facebook has offered advertisers more strategic value than perhaps any other social network. It has accomplished this with a mix of strategic vehicles, including targeted display ads and sponsored stories, branded profiles known as Facebook Pages, a developer incentive program to encourage content development, and a social news feed of brand-related user behavior (Facebook Beacon).

Facebook Social Ads are targeted at specific users based on member profiles and behavior in the network. Facebook Pages are brand equivalents to user profiles. They can be enhanced with applications from the business itself and from developer widget applications.

The free developers feature enables programmers to create widgets, mash-ups, tools, and projects for Facebook users. These small applications are popular with consumers and are useful to brands that utilize them to maintain a presence on user profiles. For example, FaceBank is a widget that enables Facebook users to track expenses (and share information about expenses with friends).

Facebook Beacon offers brands a way to virally distribute information about user brandrelated activity. News feeds notify friends of a user's engagement with a brand's profile and website along with specific product search history and purchases. The news feed stories act as a form of word-of-mouth promotion. Beacon offers a potentially powerful way to utilize the influence tactic of social proof, the influence a group of others have over a consumer's decision. 


\section{Prominent Facebook Pages in the Transit Industry}

\section{1,000,000 People against the NYC MTA Fare Hike}

http://www.facebook.com/group.php?sid=e1e0f093148393b07b3a624abb573c1a\&gid=7 $\underline{3698246213 \& \text { ref }=\text { search }}$

\section{Twitter}

Twitter is a social networking and micro-blogging service that enables its users to send and read other users' updates known as tweets. Tweets are text-based posts of up to 140 bytes in length. Updates are displayed on the user's profile page and delivered to other users who have signed up to receive them. Senders can restrict delivery to those in their circle of friends (delivery to everyone being the default). Users can send and receive updates via the Twitter website, Short Message Service (SMS), RSS feeds (receive only), or through another application. The service is free to use over the web, but using SMS may incur phone services provider fees.

As of March 2009, Twitter has received more visibility and popularity worldwide. Twitter is often described as the 'SMS of the Internet' in that the site provides the back-end functionality (via its APIs) to other desktop and web-based applications to send and receive short text messages often obscuring the actual website itself. This extensibility of the service has earned it more popularity than it would have garnered if users had to visit the site to use the service.

A February 2009 Compete.com blog entry ranks Twitter as the third largest social network in the world ( a sharp increase from $22^{\text {nd }}$, a year prior) and puts the number of unique monthly visitors at roughly 6 million and the number of monthly visits at 55 million. ${ }^{[3]}$

\section{Prominent Twitter Pages in the Transit Industry}

BART (Bay Area Rapid Transit) provides train service throughout the San Francisco Bay Area - http://twitter.com/sfbart

Washington State Department of Transportation - http://twitter.com/wsdot MTA N.Y.C. Transit - http://twitter.com/MTA NYC 


\section{Web Photos}

\section{Flickr}

Flickr, while not the leader in the traditional online photo market led by Kodak Gallery and Yahoo! Photos. This market is basically focused on upload/album/print capabilities and has little to none social aspects. Flickr is the clear leader in the social photo sharing market with its unmatched community, features, and usability.

Flickr asks photo submitters to organize images using tags (a form of metadata), which allow searchers to find images related to particular topics, such as place names or subject matter. Flickr was also an early website to implement tag clouds, which provide access to images tagged with the most popular keywords.

Flickr also allows users to organize their photos into "sets", or groups of photos that fall under the same heading. However, sets are more flexible than the traditional folderbased method of organizing files, as one photo can belong to one set, many sets, or none at all. Flickr's "sets", then, represent a form of categorical metadata rather than a physical hierarchy. Sets may be grouped into "collections", and collections further grouped into higher-order collections.

Finally, Flickr offers a fairly comprehensive web-service API that allows programmers to create applications that can perform almost any function a user on the Flickr site can do.

\section{Prominent Flickr Pages in the Transit Industry}

Seattle Transit Blog

http://www.flickr.com/groups/seatrans/pool/

Transportation for America

http://www.flickr.com/groups/t4americal

\section{Web Video}

YouTube - Founded in February 2005, YouTube is the leader in online video, and the premier destination to watch and share original videos worldwide. YouTube is most often mentioned during discussions of user generated content, viral video, and social media space, and less so during discussions of social networking. YouTube is gender 
neutral (53 percent of users are Male), but is not ethnically diverse (92 percent of users are white). Though it has diversity among age groups, it is heavily used by teens and young adults. Advertisers can post directly to YouTube or let posts occur organically by enabling brand fans to capture video and post to the site.

Posting videos and encouraging fans are perhaps the most obvious use of this social network of advertising, but two other options are notable. First, YouTube offers Community links, which can be branded like brand profiles on MySpace and Facebook. Second, the Community area of YouTube features a list of contests sponsored by brands seeking consumer-generated advertising. The videos posted on the contest sites serve as promotional pieces for the brand and the site becomes a promotional vehicle and hosting service for the brands.

Ultimately, branding on social-networking sites promotes brand awareness, brand recall, and if done well, builds on brand loyalty and brand equity. However, social networking is not without its flaws. Online advertising still suffers from the limitations facing all forms of advertising. Clutter is a tremendous distraction for people as they are faced with advertising in and on every imaginable media.

Social networks offer the greatest benefits to brands when the brands play to a network's culture, developing brand personas and engaging in dialogue. However the workhorse of social network advertising is still the display ad. Unfortunately display ads are not nearly as effective on social networking sites as they are on other types of websites and clickthrough rates are much lower.

\section{Transit Video Contests}

http://urbanplacesandspaces.blogspot.com/2008/06/us-pirg-transit-video-contest.html http://www.uspirg.org/transit-video-contest/submissions

\section{Wikis}

A wiki is a page or collection of Web pages designed to enable anyone who accesses it to contribute or modify content (excluding blocked users), using a simplified markup language. Wikis are often used to create collaborative websites and to power community websites. Wikis are used in business to provide intranet and knowledge management systems. The collaborative encyclopedia Wikipedia is one of the bestknown wikis. 


\section{Prominent Wikis in the Transit Industry}

\section{Chicago Transit}

http://chicagowiki.transitapi.com/

http://wiki.openstreetmap.org/wiki/Category:Transit

\section{San Francisco Bay Area}

http://headwayblog.com/wiki/index.php?title=San Francisco Bay Area Transit wiki

This project aims to be a community-maintained repository for transit information in the SF Bay Area, much like the old transitinfo.org project (which was co-opted into transit.511.org).

\section{Transit in Canada}

\section{http://transitwiki.ca/wiki/Transitwiki.ca}

This is a collaborative effort to collect information on transit systems and policies across Canada. We hope that the information will be useful in bringing about improvements to public transportation nationwide.

\section{Virtual Worlds}

Virtual worlds take the idea of social networking to the next level by taking it to the next dimension ( $3 d$ versus $2 d$ ), the degree of immersion, one's representation and control of identity in the space, the sense of "presence" with others in the same time and place, and complexity. During a session in a virtual world, the quality of the interface, the colors, sounds, and visual textures enhance the sense of being in the space. Participants move and communicate via visual representations of their identity called avatars.

Virtual worlds may be classified as being open or closed. Open worlds are managed and hosted by an organization that offers opportunities for brands to engage in the community. A closed, branded space on the other hand are managed by a major corporation (Coca-Cola Company or MTV for example) and therefore are closed from outside development or marketing.

An example of an open world and currently the most popular world is Second Life (SL). Second Life was developed by Linden Lab and launched on June 23, 2003. A free client program called the Second Life Viewer enables its users, called Residents, to interact 
with each other through avatars. Residents can explore, meet other residents, socialize, participate in individual and group activities, and create and trade virtual property and services with one another, or travel throughout the world, which residents refer to as the grid. Second Life caters for users aged over eighteen, while its sister site Teen Second Life is restricted to users aged between thirteen and eighteen.

Built into the software is a three dimensional modeling tool based around simple geometric shapes that allows a resident to build virtual objects. This can be used in combination with the Linden Scripting Language which can be used to add functionality to objects. More complex three dimensional Sculpted prims (colloquially known as sculpties), textures for clothing or other objects, and animations and gestures can be created using external software. The Second Life Terms of Service ensure that users retain copyright for any content they create, and the server and client provide simple digital rights management functions.

Second Life has an internal currency, the Linden dollar (L\$). L\$ can be used to buy, sell, rent or trade land or goods and services with other users. Virtual goods include buildings, vehicles, devices, animations, clothing, skin, hair, jewelry, flora and fauna, and works of art. Services include "camping", wage labor, business management, entertainment and custom content creation. $L \$$ can be purchased directly from Linden Lab, independent brokers or other users. Money obtained from currency sales is most commonly used to pay Second Life's own subscription and tier fees; only a relatively small number of users earn large amount of money from the virtual world.

Open virtual worlds currently have limited implications for marketing brands as the adoption rate is much slower than $2 \mathrm{~d}$ social networks due to relatively steep learning curve for joining a virtual world.

\section{Google}

Google is the industry leader in search, but they do so much more than that. Google's mission is to organize the world's information and make it universally accessible and useful.

As a first step to fulfilling that mission, Google's founders Larry Page and Sergey Brin developed a new approach to online search that took root in a Stanford University dorm room and quickly spread to information seekers around the globe. Google is now widely 
recognized as the world's largest search engine -- an easy-to-use free service that usually returns relevant results in a fraction of a second.

When you visit www.google.com or one of the dozens of other Google domains, you'll be able to find information in many different languages; check stock quotes, maps, and news headlines; lookup phonebook listings for every city in the United States; search billions of images and peruse the world's largest archive of Usenet messages -- more than 1 billion posts dating back to 1981 .

Google's utility and ease of use have made it one of the world's best known brands almost entirely through word of mouth from satisfied users. As a business, Google generates revenue by providing advertisers with the opportunity to deliver measurable, cost-effective online advertising that is relevant to the information displayed on any given page. This makes the advertising useful to you as well as to the advertiser placing it. They believe you should know when someone has paid to put a message in front of you, so they always distinguish ads from the search results or other content on a page. They don't sell placement in the search results themselves, or allow people to pay for a higher ranking there.

In Jeff Jarvis's 2009 book, What Would Google Do?, he explains the new rules of a new age and how Google is the only one that understands how to survive and prosper in this new age. Google operates under these new rules:

- Customers are now in charge. They can be heard around the globe and can have an immediate impact on huge institutions.

- People can find each other anywhere and coalesce around you - or against you

- The mass market is dead, replaced by the mass of niches.

- The key skill in any organization today is no longer marketing but conversing.

- We have shifted from an economy based on scarcity to one based on abundance. The control of products or distribution will no longer guarantee a premium and a profit.

- Enabling customers to collaborate with you - in creating, distributing, marketing, and supporting products - is what creates a premium in today's market.

- The most successful enterprises today are networks and the platforms on which those networks are built.

- Owning pipelines, people, products, or even intellectual property is no longer the key to success. Openness is. 
In the $2^{\text {nd }}$ part of the book, Jeff applies Google's new rules to various industries such as the media, advertising, retail, utilities, manufacturing, service, money, public welfare, and public institutions. He describes what these industries might look like and do if Google was calling the shots. Although he does not specifically mention public transportation, there are a few sections that are worth exploring for this literature review.

As a utility, Google would find a way to create more energy and manage abundance rather than try to control the scarcity of resources. Google is supporting an electric-car initiative called RechargelT, which is trying to accelerate the adoption of plug-in hybrid cars. Google would also give us data about how we used our power by each device. That data would tell us how to conserve (making us smarter) and it would tell Google how we live (making it smarter). Under the RechargelT progam, Google is also encouraging alternate forms of commuting by offering a free car-sharing program to its employees at its Mountain View, CA headquarters. This program provides employees who come to work by carpooling, taking public transport, riding the Google shuttle, or self-powered commuting (bicycling, walking, etc.) with the ability to use a car during the day. This corporate car-sharing program enables employees who need to go to business meetings or run errands to avoid driving to work in a single occupant vehicle. This program is based on a partnership with Enterprise Rent-A-Car who manages the fleet. http://www.google.org/recharge/overview.html

As a service (the example given in the book is an airline, but it could be applied to other forms of public transportation), Google would enable customers to connect with each other. Passengers could set up chats and social networks around flights and destinations so they could hook up before and during the flight. They could organize to share cabs one they land. They could ask fellow passengers for tips about restaurants, museums, and stores and ways to get around. They would make the flight a social experience in which travelers could find people they want to meet. Airlines in turn could market specific flights based on the passengers traveling. These networks also raise the possibility of creating new economy around the flight. Airlines could set up auction marketplaces for some seats and then use this information to forecast and maximize load. All of this leads to increased efficiency and profitability for the airline and bargains and flexibility for the passengers.

\section{Google Transit}

In December 2005, Google launched Google Transit. This is a web application (listed in Google Labs), that plans a trip using public transportation options. Google Transit launched with support for Portland, Oregon. Information for Eugene, Oregon; $\underline{\text { Honolulu, }}$ 
Hawaii; Pittsburgh, Pennsylvania; Seattle, Washington; and Tampa, Florida was added on September 27, 2006, $\stackrel{[19]}{ }$ with more added since including adding cities in Canada, Europe, Japan and Australia. The service calculates route, transit time and cost, and can compare the trip to one using a car. There are now more than 256 cities covered with Google Transit.

The GoogleTransitDataFeed Open Source Software project is an effort to offer tools for reading, writing, and converting to and from the Google Transit Feed Specification format, to help make public transit information projects more successful for agencies and other interested parties.

The project currently offers code for working with transit data in the Java and Python languages.

For information on the project in general, please visit the wiki pages and the project main web site http://www.googletransitdatafeed.org

\section{Google Maps}

Google Maps (for a time named Google Local) is a free web mapping service application and technology provided by Google that powers many map-based services including the Google Maps website, Google Ride Finder, Google Transit and embedded maps on third-party websites via the Google Maps API. It offers street maps, a route planner for traveling by foot, bicycle, car, or public transport and an urban business locator for numerous countries around the world. It also can help with finding businesses.

\section{Google Maps for Mobile}

Google maps for mobile, make it easy to get public transit directions while you're out and about in more than 50 cities worldwide and allows users to quickly access information for subway, bus, and train routes.

\section{Google Maps on a Phone}

- My Location (watch video). See your location on a map, even if you don't have GPS.

- Business listings. Search for any business or category of interest.

- Driving directions. Thanks to My Location, you don't even have to enter your starting point. 
- Transit \& walking directions (watch video). Get routes and schedules to travel via subway, bus, or on foot.

- Street View (watch video). View street-level imagery of businesses and turns in directions.

- Traffic. Real-time traffic helps you find the fastest route.

- Enterprise. BlackBerry administrators can deploy Maps for BlackBerry Enterprise Server.

A related product is Google Earth, a stand-alone program for Microsoft Windows, Mac OS X, Linux, SymbianOS and iPhone OS which offers more globe-viewing features Google Earth is a virtual globe, map and geographic information program that was originally called Earth Viewer, and was created by Keyhole, Inc, a company acquired by Google in 2004. It maps the Earth by the superimposition of images obtained from satellite imagery, aerial photography and GIS $\underline{3 D}$ globe. It is available under three different licenses: Google Earth, a free version with limited functionality; Google Earth Plus (discontinued), which included additional features; and Google Earth Pro (\$400 per year), which is intended for commercial use.

The product, re-released as Google Earth in 2005, is currently available for use on personal computers running Microsoft Windows 2000, XP, Vista, Mac OS X 10.3.9 and above, Linux (released on June 12, 2006), and FreeBSD. Google Earth is also available as a browser plugin (released on June 2, 2008) for Firefox, Safari 3 , IE6 and IE7. It was also made available on the iPhone OS on October 27, 2008, as a free download from the App Store. In addition to releasing an updated Keyhole based client, Google also added the imagery from the Earth database to their web based mapping software. The release of Google Earth in June 2005 to the public caused a more than tenfold increase in media coverage on virtual globes between 2005 and 2006, ${ }^{[2]}$ driving public interest in geospatial technologies and applications.

\section{Google Street View}

On May 25, 2007, Google released Street View, a new feature of Google Maps which provides $360^{\circ}$ panoramic street-level views of various U.S. cities. On this date, the feature only included five cities, but has since expanded to thousands of locations in the United States, France, Italy, Spain, Australia, New Zealand and Japan.

In August 2008, Australia was added to the Street View feature with nearly all Australian highways, roads and streets having the feature. In addition in that month Japan was added and the Tour de France route was added on July 2 of that year. In December 
2008, New Zealand was added to street view. Australia and New Zealand are the only countries to date with almost all roads and highways featured.

Google Street View has also gained a significant amount of controversy in the days following its release; privacy concerns have erupted due to the uncensored nature of its panoramic photographs.

\section{Google Mashups}

In web development, a mashup is a Web application that combines data from one or more sources into a single integrated tool. The term Mashup implies easy, fast integration, frequently done by access to open APIS and data sources to produce results that were not the original reason for producing the raw source data. An example of a mashup is the use of cartographic data from Google Maps to add location information to real estate data, thereby creating a new and distinct Web service that was not originally provided by either source.

Content used in mashups is typically obtained from a third party source through a public interface or API (web services). Other methods of obtaining content for mashups

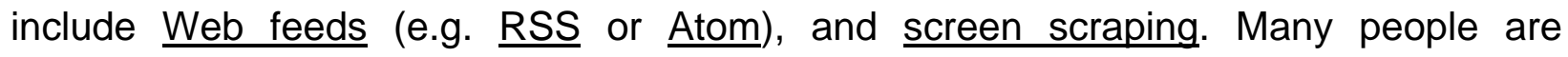
experimenting with mashups using Amazon, eBay, Flickr, Google, Microsoft, Pictometry, Yahoo, and YouTube APIs, which has led to the creation of mashup editors. Mashups and meshups are both referred to in common parlance as mashups, but they have some key differences. Mashups are a brute force joining of disparate Web Data, oblivious to the underlying Data Model(s), and often based on RSS 2.0 (a Tree Structure that contains untyped or meaning-challenged links). Meshups are a natural joining of disparate Web Data, driven by the Data Model(s), and based on selfdescribing RDF data (the links are typed, providing context by inherent meaning). ${ }^{[1]}$

A mashup or meshup Web application has two parts:

- A new service delivered through a Web page, using its own data and data from other sources.

- The blended data, made available across the Web through an API or other protocols such as HTTP, RSS, REST, etc.

The client generally accesses the mashup by using a Web browser displaying a Web page containing the mashup. Various mashup platforms support the emission of RSS, Web Services, instant messages or email messages, which are in turn consumed by feed readers, rich applications, IM clients, or email clients respectively. 
Mashups and meshups are different from simple embedding of data from another site to form a compound page. A site that allows a user to embed a YouTube video for instance, is not a mashup site. A mashup or meshup site must access third-party data and process that data to add value for the site's users. Mashups typically "screenscrape" or use other brute-force methods to access the untyped linked data; meshups typically use APIs to access typed linked data.

\section{Types of Mashups}

There are many types of mashups, such as consumer mashups, data mashups, and Business Mashups. The most common mashup is the consumer mashup, which are aimed at the general public. Examples include Google Maps, iGuide, and RadioClouds. Data mashups combine similar types of media and information from multiple sources into a single representation. An example is the Havaria Information Services' AlertMap, which combines data from over 200 sources related to severe weather conditions, biohazard threats, and seismic information, and displays them on a map of the world. Business mashups focus data into a single presentation and allow for collaborative action among businesses and developers.

\section{Conclusion}

Social media has proven to be a powerful and cost-effective communication tool for many organizations across the globe. It is important to point out, however, that though all outlets are free to join, they do have significant time considerations. For many, time is money. Social media is a dynamic field that requires constant research and monitoring and cannot be relegated solely to normal business hours. As such, agencies must be ready to respond at any time. Today, even many traditional outlets are tapping into social media tools to broadcast consumer news. Front page stories, radio interviews, and television programming is being built around consumer-generated content. These tools give full and direct access to their target audiences. What's more, these tools allow them not only to push information outward, but interact with their users throughout the process.

In this sense, anyone with a computer and content can become an instant journalist. Certainly with interaction and consumer-generated information, comes risk. Many organizations are fearful of losing control over their brand and message. However, consumers and end-users can affect and discuss transportation via these social media 
outlets regardless of whether transit agencies or commuter services organizations have an account or not.

Specifically for transit or commuter organizations, the constant motion of activity engenders the unique need to keep users up-to-date. These new media platforms allow for more personalized real-time communication that can yield results such as increased ridership, awareness, and community support from stakeholders. One of the key benefits of social media as a communication tool is its flexibility. These tools have the ability to take on many shapes and sizes depending on your organizational goals and needs. Social media can be used as a PR tool not only for promoting events and updates, but also for crisis control and prevention. It gives agencies the opportunity to frame a story and release all of the applicable facts to the public before traditional media has an opportunity to broadcast the news.

Social media can also be used as a marketing tool helping to engage, educate, and inform users about the services their local public transit agencies offer. Engaging users online can foster a positive relationship between agencies and potential consumers. The personalized nature of social media can result in strengthened community partnerships and outreach. If your efforts are successful, this positive experience will encourage those same users to utilize public transit.

Social media can also be used as a customer relations tool, where the efforts of transit call centers can also be devoted to monitoring and responding to customers via social media. Often times, users are more apt to complain about an issue using a social media tool than they would via phone call or letter. By monitoring keywords, agencies will be able to respond to complaints you were previously unaware of, and preempt backlash that could grow from a user's negative experience.

Connecting with consumers means agencies must evaluate and understand where they are communicating. By turning a blind eye to these online tools, agencies risk overlooking key segments of the population. In fact, larger transit agencies who are leading the way in social media have found that by incorporating online tools with more traditional media, they have been successful in growing overall system ridership. A great example of this is the Redwood Transit System, which posted a more than 40 percent increase in ridership after uploading route information to Google Transit. As Jim Allison from BART recently said in a Youtube ${ }^{\mathrm{TM}}$ video sponsored by the Federal Transit Administration, "San Francisco I think is now where maybe the rest of the country will be in just a few years... While we may be ahead of the curve, I don't think we are riding a flash in the pan here." 